\title{
Ozone and temperature decadal responses to solar variability in the stratosphere and lower mesosphere, based on measurements from SABER on TIMED
}

\author{
Frank T. Huang ${ }^{1, *}$, Hans G. Mayr ${ }^{2}$, James M. Russell III ${ }^{3}$, and Martin G. Mlynczak ${ }^{4}$ \\ ${ }^{1}$ University of Maryland, Baltimore County, MD 21250, USA \\ ${ }^{2}$ NASA Goddard Space Flight Center, Greenbelt, MD 20771, USA \\ ${ }^{3}$ Hampton University, Center for Atmospheric Sciences, Hampton, VA 23668, USA \\ ${ }^{4}$ NASA Langley Research Center, Hampton, VA 23681, USA \\ *retired
}

Correspondence to: Frank T. Huang (fthuang@verizon.net)

Received: 3 May 2016 - Revised: 5 August 2016 - Accepted: 6 September 2016 - Published: 20 September 2016

\begin{abstract}
We have derived ozone and temperature responses to solar variability over a solar cycle, from 2002 to 2014 at $20-60 \mathrm{~km}$ and $48^{\circ} \mathrm{S}-48^{\circ} \mathrm{N}$, based on data from the Sounding of the Atmosphere using Broadband Emission Radiometry (SABER) instrument on the Thermosphere-IonosphereMesosphere Energetics and Dynamics (TIMED) satellite. Simultaneous results for ozone and temperature with this kind of spatial coverage have not been previously available, and they provide the opportunity to study correlations between ozone and temperature responses. In previous studies, there has not been general agreement on the details or, at times, even the broad behavior of the responses to decadal solar variability. New results from a different dataset should supply new information on this important and interesting subject. A multiple regression is applied to obtain responses as a function of the solar $10.7 \mathrm{~cm}$ flux. Positive responses mean that they are larger at solar maximum than at solar minimum of the solar cycle. Both ozone and temperature responses are found be positive or negative, depending on location.

Generally, from $\sim 25$ to $60 \mathrm{~km}$, the ozone and temperature responses are mostly out of phase (negatively correlated) with each other as a function of solar variability, with some exceptions in the lower altitudes. These negative correlations are maintained even though the individual ozone (temperature) responses can change signs as a function of altitude and latitude, because the corresponding temperature (ozone) responses change signs in step with each other. From $\sim 50$ to $60 \mathrm{~km}$, ozone responses are relatively small, varying from
\end{abstract}

$\sim-1$ to $\sim 2 \% 100 \mathrm{sfu}^{-1}$ (solar flux units), while tempera-

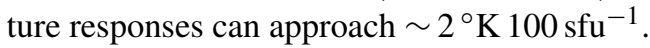

From $\sim 25$ to $\sim 40 \mathrm{~km}$, the ozone responses have become mostly positive at all latitudes and approach a maximum of $\sim 5 \% 100 \mathrm{sfu}^{-1}$ near the Equator and $\sim 30-35 \mathrm{~km}$. In contrast, at low latitudes, the temperature responses have become negative but also reach a local maximum (near $32 \mathrm{~km}$ ) in magnitude. The ozone and temperature responses remain mostly out of phase, with isolated exceptions at midlatitudes between $\sim 25$ and $45 \mathrm{~km}$. The general negative correlations are consistent with the idea that photochemistry is more in control in the upper stratosphere and lower mesosphere.

The correlation coefficients between the solar $10.7 \mathrm{~cm}$ flux and the ozone and temperature themselves from 2002 to 2014 are positive (negative) in regions where the responses are positive (negative). This supports our results since the correlations are independent of the multiple regression used to derive the responses. We also compare with previous results.

Keywords. Atmospheric composition and structure (middle atmosphere - composition and chemistry)

\section{Introduction}

The response of atmospheric ozone and temperature to solar variability over a solar cycle ( $\sim 11$ years) has been investigated over the years for both scientific and practical reasons, such as their potential effect on climate (e.g, Austin et al., 
2008). In recent years, advances in theoretical studies such as 3-D coupled chemistry climate models, in conjunction with empirical results, have advanced our understanding considerably. However, there has not been uniform agreement between models and empirical studies, or even among models or empirical studies themselves (e.g., see Austin et al., 2008; Crooks and Gray, 2005). Models must deal with inherent complexities of the physical processes, and measurements are challenging due to the need for quality global-scale measurements over one or more solar cycles.

New results from a different dataset should supply new information on this important and interesting subject. In addition, simultaneous results for ozone and temperature with this kind of spatial coverage have not been previously available, and they provide the opportunity to study the correlation and phase relations between ozone and temperature responses. These correlations will provide new information concerning the relative importance of photochemistry and dynamics related to ozone and temperature.

In the following, we focus on empirical results of ozone and temperature responses to solar variability over a solar cycle in the stratosphere and lower mesosphere. We provide new results from June 2002 through June 2014, from 20 to $60 \mathrm{~km}$ and $48^{\circ} \mathrm{S}$ to $48^{\circ} \mathrm{N}$ latitude, based on measurements from the Sounding of the Atmosphere using Broadband Emission Radiometry (SABER) instrument (Russell III et al., 1999) on the Thermosphere-Ionosphere-Mesosphere Energetics and Dynamics (TIMED) satellite. The data are unique in the breadth of their information content, having been made over the globe from 20 to $100 \mathrm{~km}$ over $24 \mathrm{~h}$ in local solar time (LST) since the beginning of 2002. Measurements of ozone and temperature that are colocated, with this detailed space-time coverage, from one instrument have not been available previously.

This is a companion paper to Huang et al. (2016), which presented parallel results, albeit from 50 to $100 \mathrm{~km}$ in the mesosphere and lower thermosphere. There have been previous results of responses also based on SABER data by Nath and Sridharan (2014). However, their results are given only in one latitude band from 10 to $15^{\circ} \mathrm{N}$, and they do not appear to have accounted for diurnal variations inherent in the SABER measurements.

We also compare with results by others using previous measurements made by other satellites. However, operational satellites, which are meant to provide measurements over the longer term of decades or more, have had intermittent problems such as calibration and continuity between different satellites.

Also, other satellite data that were used in previous studies provided measurements at only one or two fixed local times. SABER measures over the $24 \mathrm{~h}$ of local times, thereby providing the opportunity to derive the variations of ozone and temperature as a function of local time and to obtain zonal means that are consistent averages of variations over longitude and local time. This also makes it straightforward to compare directly with 3-D models (Austin et al., 2008). In addition, as discussed below, results based on data measured at a specific local time may be biased by the variations with local time.

Previous empirical results, based on a combination of satellite and ground-based measurements, do cover a larger latitude range than we present here, but there are gaps in overall altitude and latitude coverage, compared to SABER, with latitude and altitude resolutions of $4^{\circ}$ and $2.5 \mathrm{~km}$.

Data from the Halogen Occultation Experiment (HALOE) on the Upper Atmosphere Research Satellite (UARS) contain the majority of the coverage provided by SABER measurements, although the measurements are made only at sunset and sunrise. Nevertheless, we will see below that comparisons of results based on HALOE data with our results are more fruitful than comparisons with results based on other measurements.

\section{Data characteristics and analysis}

SABER ozone and temperature measurements have been analyzed with success for more than a decade. We have derived variations with periods from 1 day or less (diurnal variations) up to multiple years (semiannual oscillations (SAOs) and quasi-biennial oscillations (QBOs)) and 1 decade or more (trends). See Huang et al. (2008a, b, 2010a, b, 2014). Zhang et al. (2006) and Mukhtarov et al. (2009) have derived temperature diurnal tides using SABER data, and Nath and Sridharan (2014) have also derived results of response to solar variability using SABER data. However, as noted earlier, they obtained results only at $10-15^{\circ}$ latitude, and it does not appear that they have accounted for diurnal variations of the SABER measurements (see Sect. 4.2 and discussion related to Fig. 4).

For both ozone and temperature, these studies show that, for variations that are deviations from a mean state (e.g., diurnal variations, tides, SAOs, QBOs, trends), SABER measurements are robust and precise. For example, zonal mean tidal temperatures can agree with other measurements to within $\sim 1^{\circ} \mathrm{K}$ (Huang et al., 2010a), and our zonal mean ozone diurnal variations can agree with other diurnal measurements to within less than a few percent (Huang et al., 2010a). Deviations from a mean state also include variations such as trends (Huang et al. 2014) and, what is relevant here, responses to solar variability. It is the systematic uncertainties (accuracy) that can be larger.

\subsection{Data characteristics}

The data are provided by the SABER project (version 2.0, level2A). They are interpolated to $4^{\circ}$ latitude and $2.5 \mathrm{~km}$ altitude grids, after which zonal averages are taken for analysis.

A feature of SABER data is that, unlike other satellites, the orbital characteristics of TIMED are such that SABER 
samples over the $24 \mathrm{~h}$ of local time, which can be used to estimate diurnal variations of ozone and temperature (e.g., thermal tides). Variations with local time are especially important in the mesosphere and lower thermosphere, where the ozone and temperature diurnal amplitudes can be dominant. Even in the stratosphere, ozone and temperature diurnal variations may not be negligible (Huang et al., 2010a, b). A complication is that it takes SABER 60 days to sample over the $24 \mathrm{~h}$ of local time. Over this period, the variations with local time are embedded with the seasonal variations and need to be separated from them. The method we use estimates both the diurnal and mean variations (e.g., seasonal, semiannual, annual) together, by performing a least-squares fit of a twodimensional Fourier series, where the independent variables are local time and day of year. The algorithm is discussed further in Huang et al. (2010a, b).

\subsection{Data analysis}

\subsubsection{Estimation of variations with the solar cycle}

The variations with solar activity, as represented by the $10.7 \mathrm{~cm}$ solar flux, are estimated in a similar manner as previously done by others, using a multiple regression analysis (e.g., Keckhut et al., 2005; Soukharev and Hood, 2006; Bevington and Robinson, 1992) that includes solar activity, trends, seasonal variations, QBO, and local time terms on monthly values.

Specifically, the estimates are found from a multiple regression (least-squares) analysis of the equation

$$
\begin{aligned}
M(t)= & a+b \times t+d \times \mathrm{F} 107(t)+c \times S(t) \\
& +l \times 1 \mathrm{st}(t)+g \times \mathrm{QBO}(t),
\end{aligned}
$$

where $t$ is time (months), $M(t)$ stands for the ozone mixing ratio or temperature measurements, $a$ is a constant, $b$ is the trend, $d$ is the coefficient for solar activity ( $10.7 \mathrm{~cm}$ flux), $c$ is the coefficient for the seasonal $(S(t))$ variations, $l$ is the coefficient for local time (lst) variations, and $g$ is the coefficient for the QBO. As is often done, the seasonal and local time variations are removed first, but we include them in Eq. (1) for completeness. The F107 stands for the solar $10.7 \mathrm{~cm}$ flux, which is commonly used as a measure of solar activity, and the values used here are monthly means provided by NOAA. This algorithm is applied to zonal mean monthly values of SABER data from June 2002 through June 2014 (as in Fig. 1), from $48^{\circ} \mathrm{S}$ to $48^{\circ} \mathrm{N}$ latitude and from 20 to $100 \mathrm{~km}$. Equation (1) has also been used by others and by us to estimate corresponding ozone and temperature trends (Huang et al., 2014).

Equation (1) is basically the same as that used by most others in previous studies, sometimes with variants. Additional terms such as that for the El Niño-Southern Oscillation (ENSO) and variants in the QBO term are sometimes used. As discussed below in reference to Fig. 4, Nath and Sridharan (2014) have analyzed the same SABER data and have included the ENSO term in addition to a two-component QBO term, and our results agree very well. Soukharev and Hood (2006) used the Mg II UV index instead of the $10.7 \mathrm{~cm}$ flux as a proxy for the solar variability, but Crooks and Gray (2005) have shown that this is not important. Although there were no volcanic eruptions that needed consideration for the SABER data, analysis of past data has sometimes included terms representing these effects (She et al., 2009).

\subsubsection{Statistical and error considerations}

Because the measurements are not exact and the nature of the terms in Eq. (1) are not ideal (e.g., not orthogonal) for multiple regression, the uncertainties of the results need to be considered. In particular, the linear trend term $(b \times t)$ and the solar response term $(d \times \mathrm{F} 107(t))$ in Eq. (1) are both of low frequency over a solar cycle, and the results can be susceptible to some degree of aliasing. Although we do not believe that it is necessary, the situation could be mitigated by longer data spans of more than one solar cycle. We will discuss these in more detail in Sect. 5 (Quality of results), after first discussing the results themselves.

\section{Results}

We use the term "response to solar activity" generally to refer to the term $d \times \mathrm{F} 107$ in Eq. (1), and specifically to ozone or temperature responses at solar maximum minus those at solar minimum, per 100 solar flux units (sfu). For ozone, it is also in terms of percentage differences. A positive response means that the response at solar maximum is larger than that at solar minimum.

\subsection{Ozone and temperature variations over a solar cycle}

We first consider the data separately from the multiple regression of Eq. (1), to give a qualitative indication of expectations.

In Fig. 1, the top left (panel a) shows our monthly zonal mean ozone (red lines) mixing ratios (part per million by volume, ppmv), at $35 \mathrm{~km}$ and the Equator from the middle of 2002 to the middle of 2014, with seasonal and local time variations removed. Also shown is the corresponding $10.7 \mathrm{~cm}$ flux (black lines, right axis scale, units in sfu). As can be seen, the year 2002 was near solar maximum, in the middle of solar cycle 23, and 2014 is some years into cycle 24, which began at $\sim 2008$. The top right (panel $b$ ) corresponds to the left panel but for temperature $(\mathrm{K})$ at $32.5 \mathrm{~km}$. The ozone and temperature zonal means are given at slightly different altitudes $(35,32.5 \mathrm{~km})$ as they correspond to the altitudes where their respective net changes from 2002 to 2009 are largest. In the following, we will not differentiate between these altitudes. 

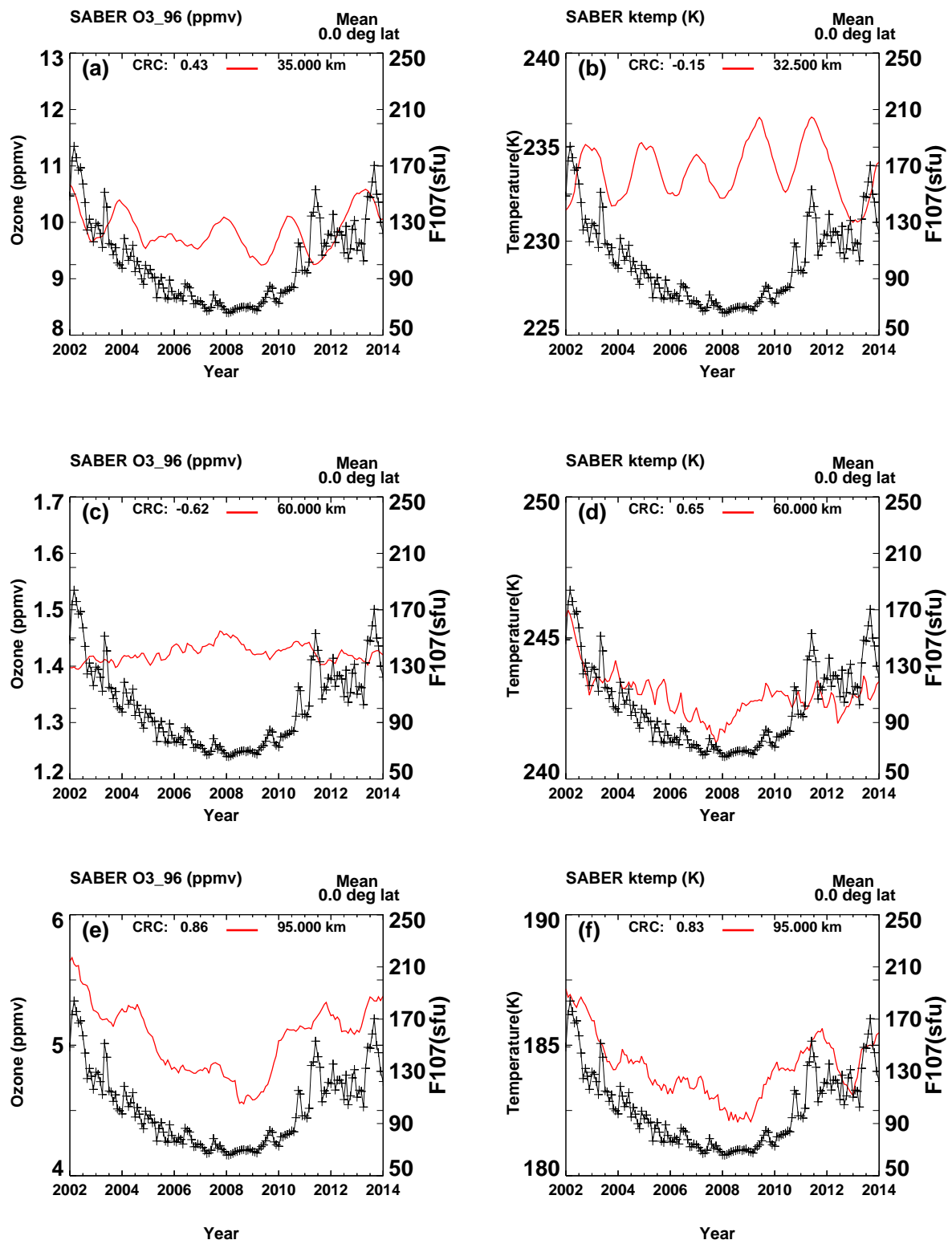

Figure 1. Top row: ozone zonal mean mixing ratios (left panel, red line, ppmv) from mid-2002 to mid-2014 at $35 \mathrm{~km}$ and $0^{\circ}$ lat; right panel, as in left panel but for temperature $(\mathrm{K})$ at $32.5 \mathrm{~km}$. Middle row: as in top row but at $60 \mathrm{~km}$. Bottom row: $95 \mathrm{~km}$. Black lines $(+$, right scale) show the corresponding monthly $10.7 \mathrm{~cm}$ flux $(\mathrm{sfu})$ provided by NOAA.

In the top left (panel a), at $35 \mathrm{~km}$, it can be seen that the ozone zonal means show a net decrease from solar maximum to solar minimum (years 2002 to $\sim 2009$ ), despite interference by the QBO. The ozone responses are then positive (decreasing with decreasing $10.7 \mathrm{~cm}$ flux). In the top right (panel b) of Fig. 1, the temperatures at $32.5 \mathrm{~km}$ show a net increase from $\sim 2002$ to 2009 , and the responses are then negative (increasing with decreasing solar flux). The ozone and temperature responses near $35 \mathrm{~km}$ are then negatively correlated (out of phase) to each other. This may be more clearly seen in Fig. 6 below (Sect. 5.3), where we have plotted the corresponding scatterplots, showing ozone and temperatures versus the $10.7 \mathrm{~cm}$ flux.

In Fig. 1, the labels "CRC" denote the correlation coefficient between the ozone and temperature zonal means and the $10.7 \mathrm{~cm}$ flux. At $35 \mathrm{~km}$ and the Equator, the correlation coefficients with the $10.7 \mathrm{~cm}$ flux for ozone and temperature are 0.43 and -0.15 , respectively, consistent with our visual conclusions.

It can also be seen that the QBOs of the ozone and temperature, evident in the top row of Fig. 1, are also out of phase with each other from 2002 to 2014. 
The middle row of Fig. 1 corresponds to the upper row but for $60 \mathrm{~km}$. In the left (panel c), for ozone at $60 \mathrm{~km}$, it is evident that, unlike the case of $35 \mathrm{~km}$ (top left, panel a), the ozone increases with decreasing solar activity from $\sim 2002$ to 2008 . At $60 \mathrm{~km}$ then, the ozone response to solar activity is negative (in contrast to that at $35 \mathrm{~km}$ ). For temperature at $60 \mathrm{~km}$, the middle row of the right column (panel d) of Fig. 1 shows that the temperature decreases with solar activity, so the response is positive, opposite to that at $32.5 \mathrm{~km}$. The correlation coefficients with solar activity are -0.62 for ozone and 0.65 for temperature, again consistent with visual inferences. At $60 \mathrm{~km}$ then, the ozone and temperature responses have each changed signs compared to $35 \mathrm{~km}$. But they remain negatively correlated (out of phase) to each other, as in the case for $35 \mathrm{~km}$.

The bottom row of Fig. 1 corresponds to the other rows but for $95 \mathrm{~km}$. We will discuss their relevance below. For the present, we note that at $95 \mathrm{~km}$, unlike the situations at 60 and $35 \mathrm{~km}$, both the ozone and temperature decrease with decreasing solar activity, with correlation coefficients of 0.86 and 0.83 , respectively, resulting in positive responses and also positive correlations with each other. Note also that the ozone and temperature QBOs at $95 \mathrm{~km}$ are now in phase, unlike those at lower altitudes.

These will be quantified, and for other altitudes and latitudes as well, in the next section.

\subsection{Responses of ozone and temperature to solar variability}

Here we quantify the descriptive information in Fig. 1 and expand the coverage in altitude and latitude. As noted earlier, the term response to solar activity refers to ozone or temperature solar term at solar maximum minus those at solar minimum, per 100 solar flux units (sfu). For ozone, percentage differences are used.

In Fig. 2, the left panels (a, c) of the upper and lower rows show our ozone (percent) and temperature $(\mathrm{K})$ responses to solar activity, derived using Eq. (1), on altitude-latitude coordinates from 20 to $60 \mathrm{~km}$ and $48^{\circ} \mathrm{S}$ to $48^{\circ} \mathrm{N}$. Positive values indicate that responses are larger near solar maximum relative to solar minimum and appear as brown, red, and orange colors in Fig. 2. Negative responses are in green and blue colors. Because the responses are differences of values between solar maximum and solar minimum, the colors in Fig. 2 (left panels; a, c) themselves show whether the ozone and temperature responses are positively (in phase) or negatively (out of phase) correlated to each other.

The upper right panel (b) of Fig. 2 corresponds to the left panel (a) but shows the correlation coefficients between the ozone mixing ratios themselves (see Fig. 1) and the $10.7 \mathrm{~cm}$ solar flux. It can be seen that, where the responses (left panel) are positive (negative), so are the correlations (right panel). The same is true for the temperature responses and correlations seen in the lower row of Fig. 2.
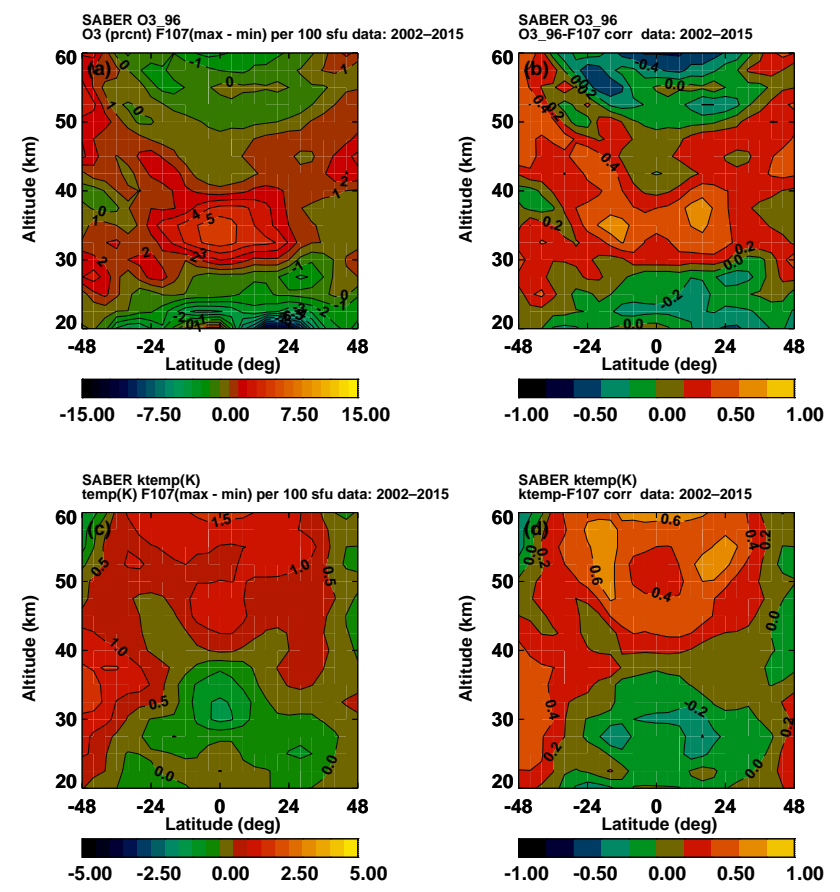

Figure 2. Ozone and temperature responses to solar variability on altitude $(20-60 \mathrm{~km})$ vs. latitude $\left(48^{\circ} \mathrm{S}\right.$ to $\left.48^{\circ} \mathrm{N}\right)$ coordinates, found by multiple regression. Top row left: ozone responses at solar maxozone responses at solar min ( $\left.\% 100 \mathrm{sfu}^{-1}\right)$; right panel: correlation coefficients between ozone mixing ratios and $10.7 \mathrm{~cm}$ flux. Bottom row: as in top row but for temperature $(\mathrm{K})$. Brown-green borders denote zero contours, with brown areas denoting positive trends.

Albeit qualitative, the correlation coefficients provide independent support for our derived responses, because they are independent of the regression (Eq. 1) used to obtain the responses in the left panels $(\mathrm{a}, \mathrm{c})$. The same holds for the temperatures. In Fig. 2 the following can be seen:

i. In the lower mesosphere from $\sim 50$ to $60 \mathrm{~km}$ and low latitudes, the ozone responses (top left, a) are negative, while the temperature responses (bottom left, c) are positive. At midlatitudes, the responses are reversed, with the ozone responses being positive and the temperature responses being marginally negative. So, between $\sim 50$ and $60 \mathrm{~km}$, the ozone and temperature responses are out of phase (negatively correlated). In this region, ozone responses are relatively small, varying from $\sim-1$ to $\sim 1 \% 100 \mathrm{sfu}^{-1}$, while temperature responses can approach $\sim 1.5^{\circ} \mathrm{K} 100 \mathrm{sfu}^{-1}$. This is consistent with the middle row of Fig. 1 at the Equator and $60 \mathrm{~km}$, where the ozone mixing ratios increase with decreasing solar activity from $\sim 2002$ to 2009 , while the corresponding temperatures decrease with decreasing $10.7 \mathrm{~cm}$ flux.

ii. From $\sim 25$ to $40 \mathrm{~km}$, the ozone responses have become mostly positive at all latitudes and approach a maximum of $\sim 5 \% 100 \mathrm{sfu}^{-1}$ near the Equator and $\sim 30-35 \mathrm{~km}$. 
In contrast, at low latitudes, the temperature responses have become negative but also reach a local maximum (near $32 \mathrm{~km}$ ) in magnitude. They remain marginally positive at midlatitudes. This is consistent with the top row of Fig. 1, where we saw that the ozone mixing ratios at $35 \mathrm{~km}$ and the Equator decreased from $\sim 2002$ to 2009 , with decreasing $10.7 \mathrm{~cm}$ flux, resulting in positive responses, while the temperatures showed a weak increase from 2002 to 2009 , resulting in negative responses, so they remain out of phase (anti-correlated) with the ozone responses.

As discussed below in Sect. 5.4, and in Fig. 1 for 95 km, it can be seen that both the ozone and temperature zonal means decrease with decreasing 10.7 flux, and so the respective responses are both positive and in phase (positively correlated). This is also consistent with the derived responses at $95 \mathrm{~km}$, seen in Fig. 7.

iii. Below $\sim 25 \mathrm{~km}$, the ozone responses are negative, reaching values $\sim-2 \% 100 \mathrm{sfu}^{-1}$, while the temperature responses are marginally positive/negative and not statistically significant.

Therefore, the ozone and temperature responses in Fig. 2 are consistent with, and quantify the discussion concerning, Fig. 1 at 35 and $60 \mathrm{~km}$.

Generally then, from $\sim 25$ to $60 \mathrm{~km}$, the ozone and temperature responses are mostly out of phase (negatively correlated) as a function of solar variability, with some exceptions in the lower altitudes. These ozone-temperature relationships can be expected, as discussed further in Sect. 5.4. In Fig. 7, we have expanded the altitude coverage to $100 \mathrm{~km}$ by including results in the mesosphere and lower thermosphere, taken from Huang et al. (2016), in order to show the systematic correlations between ozone and temperature responses over a wider altitude range.

As discussed below in Sect. 5.4, the negative ozonetemperature correlations in the upper stratosphere and the mesosphere are consistent with the idea that photochemistry, rather than dynamics, is more in control in this altitude region (Barnett et al., 1975; Finger et al., 1995; Brasseur and Solomon, 2005).

\section{Comparisons with other measurements and analyses}

Previous empirical results are based on data from the NOAA operational satellites (which include the Stratosphere Sounding Unit (SSU), the Microwave Sounding Unit (MSU), and the Solar Backscatter Ultraviolet (SBUV) instruments) from the Stratospheric Aerosol and Gas Experiment (SAGE I, II) on the Explorer and Earth Radiation Budget (ERB) satellites, from HALOE, and from ground-based instruments and rocketsondes. The advantage of the operational satellites is that they can provide global measurements covering decades, be- ing replaced as the instruments degrade. However, issues of calibration, consistency, and continuity can be problematic.

Compared to SABER, previous data cover different but larger time periods, up to two solar cycles or more. For example, the results of Hood et al. (2015), based on measurements from the SBUV measurements, span the years 19792003, while those based on SAGE II data span 1985-2005. HALOE data (Fadnavis and Beig, 2006) cover the period 1992-2004.

There have been a large amount of studies, both theoretical and empirical, over decades, and detailed comparisons are outside the scope of this work. Here, we can only present a brief comparison with previous investigations.

Our results do not compare so well with many of them, and they often do not compare especially well with each other either. The general magnitudes of our ozone and temperature responses are qualitatively similar to those of previous studies. However, they cannot be said to agree well in the details, such as the relative variations in altitude and latitude. As noted by Crooks and Gray (2005),

"In summary, [...] results support the growing body of evidence that variability associated with the 11-year solar cycle has a significant influence on stratospheric temperatures. However, there is still no consensus on the exact magnitude and spatial structure; longer and more consistent satellite observations are needed to resolve this issue."

\subsection{Comparisons of ozone}

The left panel of Fig. 3a plots our ozone responses (black line) versus altitude from 20 to $60 \mathrm{~km}$, averaged from $24^{\circ} \mathrm{S}$ to $24^{\circ} \mathrm{N}$, to better conform with results by others. We manually transferred results by others to Fig. 3, so they are not exact but should be adequate for purposes here. Also shown in Fig. 3a are results of Remsberg (2008) (light blue squares, RMSBRG) and Fadnavis and Beig (2006), denoted by green asterisks (BEIGN, $0-30^{\circ} \mathrm{N}$ ) and blue diamonds (BEIGS, 0$30^{\circ} \mathrm{S}$ ), both based on HALOE data (1992-2004). Remsberg's (2008) ozone responses for the tropics reach peaks of $\sim 2.5 \% 100 \mathrm{sfu}^{-1}$, between 30 and $40 \mathrm{~km}$. HALOE is a solar occultation experiment and measures only at spacecraft sunset and sunrise. Fadnavis and Beig (2006) noted that the values can depend on the local times of the measurements, i.e., averages of data taken. The responses of Fadnavis and Beig (2006) for the two latitude bands $\left(0-30^{\circ} \mathrm{S}, 0-30^{\circ} \mathrm{N}\right)$ do not compare so well with each other. Although there are significant differences with results by Fadnavis and Beig (2006) and Remsberg (2008), both based on HALOE data, we will see that our results are still more consistent with theirs than with results based on other data. Figure 3 a also shows ozone responses from Soukharev and Hood (2006) (AUDTA, red lines and plusses, data from 1979 to 2003), as reported by Austin et al. (2008), and from models (AUMDL, magenta lines and triangles), also reported by Austin et al. (2008), rep- 

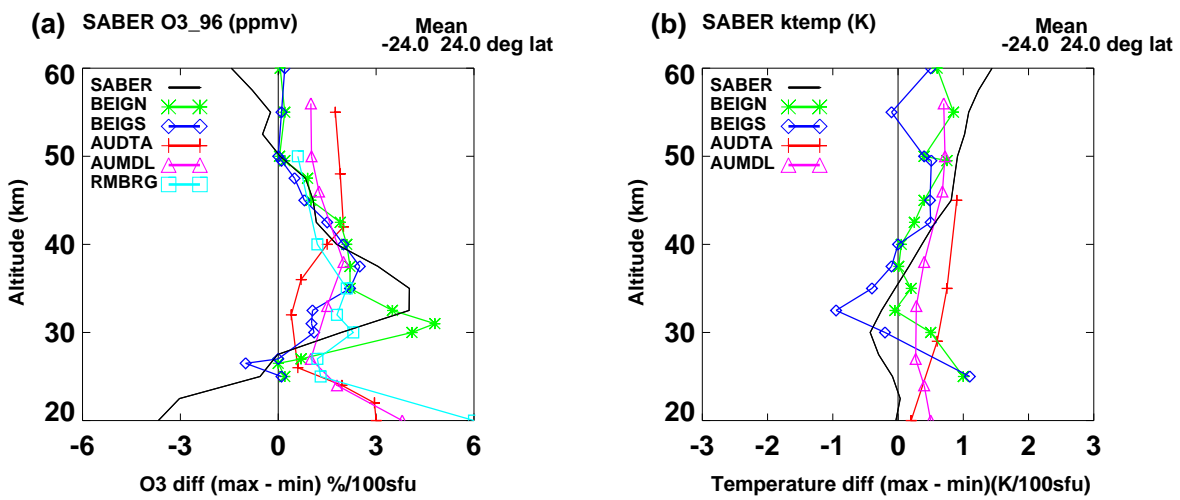

Figure 3. Ozone (left panel) and temperature (right panel) responses to solar activity versus altitude, from 20 to $60 \mathrm{~km}$. Values are responses at solar max-responses at solar min in $\% 100 \mathrm{sfu}^{-1}$ for ozone, and $\mathrm{K} 100 \mathrm{sfu}^{-1}$ for temperature. Black lines denote SABER responses at the Equator averaged from $24^{\circ} \mathrm{S}$ to $24^{\circ} \mathrm{N}$. Red plusses denote Austin et al. (2008) data (AUDTA); magenta triangles denote Austin et al. (2008) models (AUMDL); both are composited from $25^{\circ} \mathrm{S}$ to $25^{\circ} \mathrm{N}$. Green asterisks denote responses by Fadnavis and Beig (2006) for $0-30^{\circ} \mathrm{N}$ (BEIGN), and blue diamonds Fadnavis and Beig (2006) for 0-30 $\mathrm{S}$ (BEIGS). Light blue squares (RMSBRG) denote results from Remsberg (2008).

resenting composite results from $25^{\circ} \mathrm{S}$ to $25^{\circ} \mathrm{N}$ latitude. The Soukharev and Hood (2006) results (red plusses) are a composite based on SBUV, HALOE, and SAGE data, and they show a minimum near $30 \mathrm{~km}$, and a maximum above $40 \mathrm{~km}$.

Gray et al. (2005), Shindell et al. (1999), and Hood (2004) also report that the solar signal in the SBUV ozone observations is largest above $40 \mathrm{~km}$. As seen in Fig. 3a (left panel), these do not agree so well with our results, with those of Fadnavis and Beig (2006), and those of Remsberg (2008). Other studies include those of Haigh et al. (2004) and Randel and $\mathrm{Wu}$ (2007), both based on SAGE data, but there are also discrepancies among the results.

The model results in Fig. 3a (from Austin et al., 2008; magenta triangles, AUMDL) compare somewhat better with our results, in that the ozone responses are largest near $35 \mathrm{~km}$.

More recently, Hood et al. (2015) presented results based on model results from the Coupled Model Intercomparison Project, phase 5 (CMIP-5). They also included related results based on measurements from the SBUV (merged version 8, 1979-2003) and SAGE II (version 6, 1985-2005) experiments. The analysis accounted for data uncertainties including degradation with time and intercalibration offsets between different instruments. Maycock et al. (2016) have done a similar analysis on SAGE II, version 7.0 versus version 6.8. For both Hood et al. (2015) and Maycock et al. (2016), as with earlier studies in equatorial regions, ozone variations with altitude generally show minima near $30 \mathrm{~km}$, with increasing values to $40 \mathrm{~km}$ and above. The model data are generated under different conditions, and comparisons are outside the scope of this work.

More in agreement with our results is the 2-D model of Brasseur (1993), which shows that the equatorial ozone response peaks near $35 \mathrm{~km}$, with a value of $\sim 2 \%$; becomes negative near $50 \mathrm{~km}$; and reaches $\sim-0.6 \%$ between 55 and
$60 \mathrm{~km}$. They attribute the negative values to temperatureozone feedback.

\subsection{Comparisons of temperature}

The right panel in Fig. 3b corresponds to the left panel but for temperature. Unlike the case for ozone, the empirical temperature responses (AUDTA, data from 1979 to 1997) were taken by Austin et al. (2008) from Scaife et al. (2000).

In Fig. 3b, the black line denotes our responses based on SABER data, averaged from $24^{\circ} \mathrm{S}$ to $24^{\circ} \mathrm{N}$, to conform with previous results by others. The averaging over latitude smoothes the responses relative to that at the Equator and lowers the negative peak in temperature to $30 \mathrm{~km}$. The analysis of Fadnavis and Beig (2006), based on HALOE data, also shows negative temperature responses near $30 \mathrm{~km}$ for low southern latitudes (blue diamonds, BEIGS) but not for low northern latitudes (green asterisks, BEIGN). Remsberg (2008) also provides results (not shown) based on HALOE data.

The analysis of Hood (2004), based on SSU/MSU, also generates negative responses (not shown) centered near $30 \mathrm{~km}$ and compares relatively well with our results in Fig. 3b. The agreement is actually better when compared with our results that are not averaged within $\pm 24^{\circ}$ at higher altitudes. Gray et al. (2005) state, concerning the temperature responses of Hood (2004):

"This analysis employed a version of the SSU/MSU dataset corrected and compiled by the NCEP Climate Prediction Center (CPC) [...]. The analysis of Hood (2004) shows [...] the maximum positive signal over the tropics indicating a maximum value of $\sim 2 \mathrm{~K}$ near the stratopause level at $50 \mathrm{~km}(1 \mathrm{hPa})[\ldots]$. Finally, there is a region of 

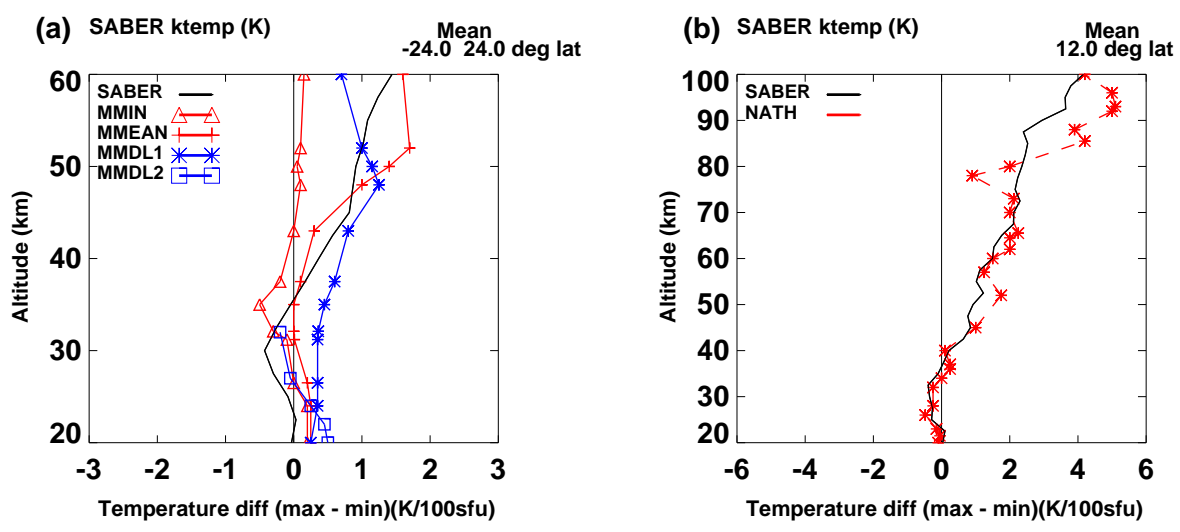

Figure 4. Left panel: black line denotes SABER responses averaged from $24^{\circ} \mathrm{S}$ to $24^{\circ} \mathrm{N}$ latitude. Red plusses denote the mean of three reanalysis datasets (MMEAN), composited from $25^{\circ} \mathrm{S}$ to $25^{\circ} \mathrm{N}$, from Mitchell et al. (2015). Red triangles corresponds to the plusses but for one set of the reanalysis data. Blue asterisks and squares denote responses of two selected models from Mitchell et al. (2015). Right panel: black line represents our SABER responses at $12^{\circ}$, from 20 to $100 \mathrm{~km}$. Red asterisks denote results of Nath and Sridharan (2014), for $10-15^{\circ} \mathrm{N}$ latitude, also based on SABER data.

negative values centred over the tropics at around $10 \mathrm{hPa}(30 \mathrm{~km})$. It is not clear why the results of Hood differ from the other two SSU studies in these respects, although the most likely difference lies in the treatments applied to the data to correct for instrument drift."

More recently, Hood et al. (2015) presented temperature responses based on ERA-Interim reanalysis data. At the Equator, the responses show a value $\sim 0.5 \mathrm{~K}$ near $25 \mathrm{~km}$, $\sim 0 \mathrm{~K}$ at $35 \mathrm{~km}$, and $\sim 1 \mathrm{~K}$ at $40 \mathrm{~km}$. This compares better in Fig. 3 with results of Fadnavis and Beig (2006) and with our results, although averaging over latitude bands must be taken into account.

To compare temperature responses further, the left panel of Fig. 4a corresponds to the right panel of Fig. 3b but shows results from Mitchell et al. (2015), based on three reanalysis datasets from operational satellites and from various models from CMIP-5 from Taylor et al. (2012). The results of Mitchell et al. (2015) were transferred manually to Fig. 4a and so are not exact. The temperature responses are composites from $25^{\circ} \mathrm{S}$ to $25^{\circ} \mathrm{N}$. Red plusses denote the mean of three results based on three sets of reanalysis data (MMEAN), and red triangles show the smaller "range" of the three results (MMIN). It can be seen that differences between the red triangles and the mean (red plusses) of three sets are significant.

Blue asterisks and squares denote responses of two selected models from Mitchell et al. (2015). The blue squares represent an atypical case of the models, to show weakly negative responses near $32 \mathrm{~km}$. They are similar to the red triangles, based on one set of reanalysis data. The responses represented by blue asterisks are more typical of the many model results shown by Mitchell et al. (2015). Although there are similarities in the relative variations with altitude among the numerous models (not shown here), the differences in the values can be large. For example, there are model responses near $50 \mathrm{~km}$ with values $\sim 0.5 \mathrm{~K}$, compared to a value larger than $1.5 \mathrm{~K}$ in Fig. $4 \mathrm{a}$. Also, at lower altitudes, the values of responses from the different models can range from slightly

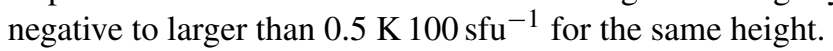

As before, the black line in the left panel of Fig. 4a represents results based on SABER data, averaged from $24^{\circ} \mathrm{S}$ to $24^{\circ} \mathrm{N}$ latitude. Like some results from Mitchell et al. (2015), this average also have negative values, but the magnitudes peak at somewhat lower altitudes, near $30 \mathrm{~km}$.

Other analyses of temperature responses include Crooks and Gray (2005), Gray et al. (2009), Keckhut et al. (2005), and Randel et al. (2009), who show only positive values. Albeit in the minority, there are several studies based on different lengths of datasets that also result in negative temperature responses near $30 \mathrm{~km}$. As described above, they include studies by Hood (2004), Fadnavis and Beig (2006), Mitchell et al. (2015), and Nath and Sridharan (2014).

The right panel of Fig. 4b, taken from Huang et al. (2016), shows our temperature responses at $12^{\circ}$ latitude (black line), along with results of Nath and Sridharan (2014) (red asterisks), at the $10-15^{\circ}$ latitude band from 20 to $100 \mathrm{~km}$. As noted earlier, the Nath and Sridharan (2014) results are also based on SABER data. We manually transferred the Nath and Sridharan (2014) results to Fig. 4b, so they are not exact. As seen in the right plot (panel b) of Fig. 4, our temperature responses agree well up to $\sim 45 \mathrm{~km}$ but not so well from $\sim 45$ to $100 \mathrm{~km}$. We believe that the differences between our results and those by Nath and Sridharan (2014), especially at higher altitudes, are due to temperature variations with local time which are embedded in the SABER data, as discussed in Sect. 2.1 ("Data characteristics"). Nath and Sridharan (2014) use "monthly averaged zonal mean" for temperature. So it 
does not appear that they have considered variations with local time (thermal tides) in their regression analysis. For temperature (and ozone), diurnal variations are relatively small below $\sim 40 \mathrm{~km}$ but can be the dominant form of variations in the mesosphere and lower thermosphere (see Zhang et al. (2006), Mukhtarov et al. (2009), and Huang et al. (2010) for temperature and Huang et al. (2008b, 2010a) for ozone). Even in the stratosphere, variations with local time may not be negligible.

\section{Quality of results}

Especially because there is not uniform agreement among the various studies, we consider the quality of our results. Uncertainties can be due to the quality of the data themselves, to the length of the data, and to the terms of the multiple regression equation.

In agreement with some other authors, as discussed below, it is likely that the main differences among the various results could be due more to the different datasets used and less to the regression analysis per se.

\subsection{SABER ozone and temperature monthly means and responses over a solar cycle}

As discussed in Sect. 3.1, it can be seen directly in Fig. 1 (top row) that at the Equator and $35 \mathrm{~km}$, from 2002 to 2009 , the ozone decreases with decreasing $10.7 \mathrm{~cm}$ flux, leading to positive ozone responses, while the temperature increases with decreasing 10.7 flux, leading to negative temperature responses. At $60 \mathrm{~km}$ (middle row), the situation is just the opposite, leading to negative responses for ozone and positive responses for temperature.

Also as discussed in reference to Fig. 6 below, where we show scatterplots for ozone and temperature monthly means versus $10.7 \mathrm{~cm}$ flux; the inferred responses are also consistent with Fig. 1.

The ozone and temperatures remain out of phase in these two altitudes, and this is consistent with the regression analysis seen in Fig. 2.

The upper and lower right panels (b, d) of Fig. 2 show the correlation coefficients between the ozone mixing ratios and temperatures themselves and the $10.7 \mathrm{~cm}$ flux. It can be seen that, where the responses (left panels a, c) are positive (negative), so are the correlations.

Again, these considerations are independent of the multiple regression, thereby lending support for our quantitative results of responses in Fig. 2.

\subsection{Standard error}

Commonly, a criterion that is used to indicate if the estimated response to solar activity is statistically significant is that its magnitude be greater than $2 \sigma$ ( $\sim 95 \%$ confidence level), where $\sigma$ is the uncertainty (standard error) of the estimated
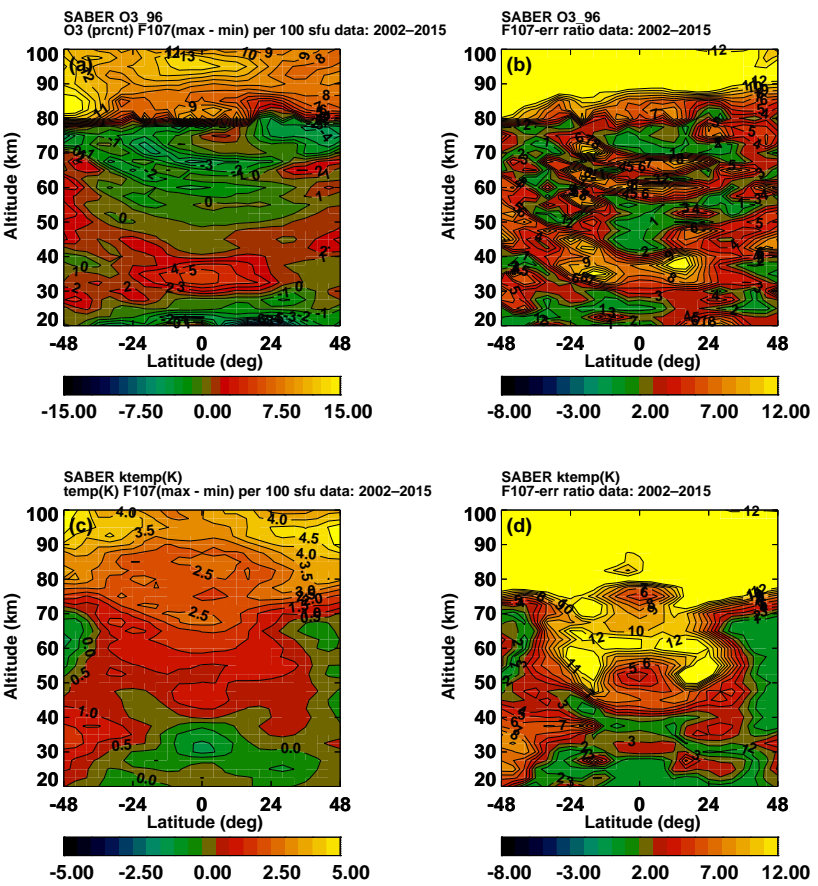

Figure 5. Top row: ozone solar responses (top left) and ratios to their respective uncertainties (top right). Bottom row: as in the top row but for temperatures. The brown colors separate those within $95 \%$ confidence ( $2 \sigma$, red, yellow) from others (green).

response and is obtained from the error matrix of the multiple regression. In our case, the uncertainties (e.g., data variances) of the SABER data themselves, which are needed for obtaining the uncertainties in the responses to solar variability, are not available. In place of the data variances, we use the sum of squares of the residuals, normalized by the number of degrees of freedom of the fit, namely, the sample variance (Bevington and Robinson, 1992). The residuals are the differences between the fit of Eq. (1) and the data.

In Fig. 5, the corresponding statistical significance of the responses to solar activity are plotted, and it can be seen that the statistical significance of the salient features of our results in Fig. 2 are generally well above the $2 \sigma$ level. The right plots (b, d; top and bottom row) show the ratios of the responses to their respective uncertainties for ozone and temperature, respectively, on altitude-latitude coordinates. The left plots $(\mathrm{a}, \mathrm{c})$ correspond to the right plots but show the corresponding responses themselves, as in Fig. 2. In the right-hand plots (b, d) of Fig. 5, the brown colors correspond to a value of 2 for the ratios of the magnitude of the responses to their respective uncertainties, $\sigma$, and mark the $95 \%$ level of statistical significance. The red and yellow colors in the right-hand plots correspond to situations that are statistically significant (greater than 2), while the green colors correspond to ratios of less than 2. The brighter yellow colors are a result of the ratios beings larger than the upper plot limit. The lower plot 

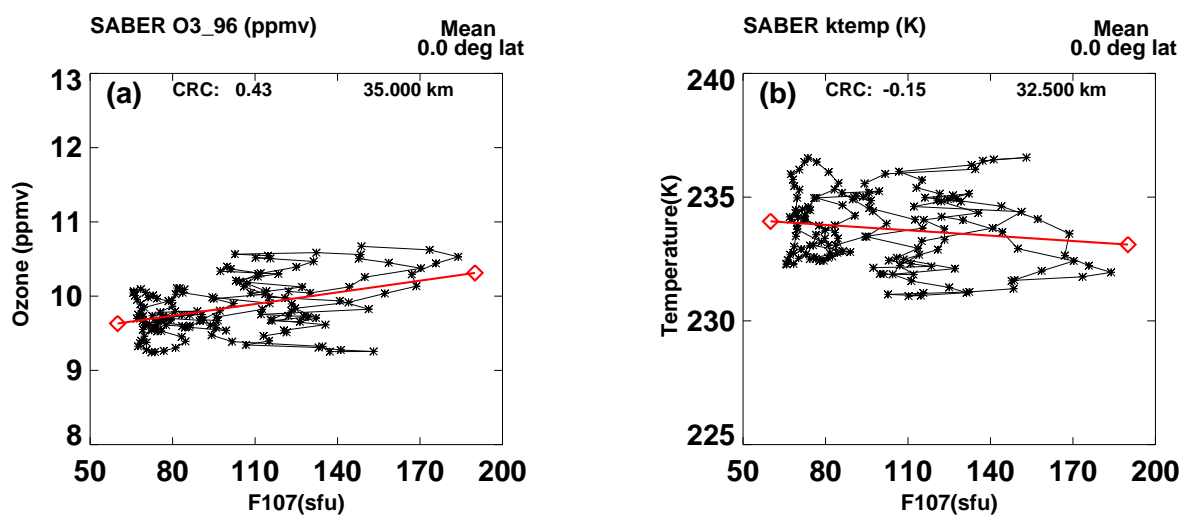

Figure 6. Left plot: scatterplot of ozone monthly values (see Fig. 1, top row) versus $10.7 \mathrm{~cm}$ flux (sfu) at $35 \mathrm{~km}$ and the Equator. Right plot: as in left plot but for temperature monthly values.

limit is set to negative so that the brown color demarks the significance of the results.

\subsection{Data length and aliasing}

The uncertainties given by the regression error matrix do not reflect potential effects such as aliasing, which could arise, for example, from the fact that the regression terms in Eq. (1) are not orthogonal. We emphasize that non-orthogonal terms do not imply that aliasing necessarily exists but should at least be considered in specific cases. In particular, the linear trend term $(b \times t)$ and the solar response term $(d \times \mathrm{F} 107(t))$ in Eq. (1) are both of low frequency over a solar cycle, and the results could be susceptible to some degree of aliasing. Although we do not believe that it is necessary, the situation could be mitigated by longer data spans of more than one solar cycle. The degree of aliasing is difficult to determine. As discussed below, we do not believe that, for us, aliasing leads to unrealistic or misleading results, although it could increase the uncertainties in our results.

Tiao et al. (1990) and Weatherhead et al. (1998, 2000), among others, have used autoregressive (AR) processes as an additional term in the regression to study the effects of aliasing. Tiao et al. (1990) used a low-frequency AR process, so that it is "confounded" with the linear trend and the solar response terms. Based on Tiao et al. (1990), for a dataset of 11 years (a bit shorter than the SABER data used), the increase in the uncertainty of the estimated trends is about a factor of 2 or less. This should be applicable to the solar response term as well, since it is also of low frequency. Tiao et al. (1990) point out that the uncertainties decrease as the length of data increases. However, we believe that it would not be as effective in our case, as well as in previous regressions by others, because the values of solar activity $(10.7 \mathrm{~cm}$ flux $)$ do not increase indefinitely with increasing data length, as does the time. Figure 6 is a scatter diagram plot of the ozone (left plot) and temperature (right plot) monthly values (as seen Fig. 1) versus the $10.7 \mathrm{~cm}$ flux. Unlike the data, where time increases monotonically with data length, the $10.7 \mathrm{~cm}$ flux values remain within a fixed interval, between solar minimum and solar maximum ( $\sim 70$ and $200 \mathrm{sfu})$, even when the measurements cover more solar cycles. In Fig. 6, the values span about one solar cycle. But even with more solar cycles, $10.7 \mathrm{~cm}$ flux values would only generally repeat and fill in with values in the same general area in Fig. 6, effectively providing a more average result but not necessarily reducing the uncertainty much otherwise.

Although visually complicated by the quasi-biennial oscillation (better seen in Fig. 1), we think that it is evident from Fig. 6 (left plot) that at $35 \mathrm{~km}$ and the Equator the ozone monthly values are positively correlated with the $10.7 \mathrm{~cm}$ flux, and the temperature monthly values (right plot) are negatively correlated with the $10.7 \mathrm{~cm}$ flux. The red line represents the results using only the solar term $d \times \mathrm{F} 107(t)$ of the multiple regression (Eq. 1). This fit leads to a response of $\sim 5 \% 100 \mathrm{sfu}^{-1}$ for ozone and a response of $\sim-1 \mathrm{~K} 100 \mathrm{sfu}^{-1}$ for temperature. Both are consistent with the regression results shown in Fig. 2, which uses all terms of Eq. (1).

Because of the consistency in the results using the multiple regression Eq. (1) and the results using only the solar term (red line), aliasing from other terms is not significant, at least for SABER data.

\subsection{Correlations between ozone and temperature responses with each other}

The ozone-temperature phase relationships (correlations) described above also serve as a test of their validity, in conjunction with previous studies.

In Fig. 7, we have expanded the altitude range of Fig. 2 to $100 \mathrm{~km}$, with information taken from Huang et al. (2016). The left panel shows ozone responses, and the right panel shows temperature responses. As can be seen, from 60 to $\sim 80 \mathrm{~km}$, the ozone responses remain mostly negative, but they become positive from $\sim 80$ to $100 \mathrm{~km}$. The temperature 
responses remain positive from 60 to $100 \mathrm{~km}$. There are exceptions near $60-70 \mathrm{~km}$ and at midlatitudes, where the ozone responses remain positive and the temperature responses remain marginally negative. In general, the ozone and temperature response continue to be out of phase up to $\sim 80 \mathrm{~km}$, and from $\sim 80$ to $100 \mathrm{~km}$ the ozone and temperature responses are in phase (positively correlated).

These changing but systematic phase relationships between the ozone and temperature responses from 20 to $100 \mathrm{~km}$ actually fit in well with previous studies of ozone mixing ratios and temperature themselves (although not specifically of the responses to solar activity between ozone and temperature), as follows.

For variations over days and longer, Barnett et al. (1975) have shown that the dependence of photochemical reaction rates on temperature, by themselves (excluding dynamics), would lead in the upper stratosphere and in the mesosphere to negative correlations (out of phase) between temperature and ozone variations over time. Quantitatively, this would depend on the details of the ozone-temperature feedback loop that is set up.

Finger et al. (1995) found that ozone and temperature variations are positively correlated (correlation coefficient) over time in the lower stratosphere and negatively correlated in the upper stratosphere, based on nearly 2 decades of satellite measurements. They used the correlation between ozone and temperature as a "sniff" test on different and new measurements.

Brasseur and Solomon (2005) have noted that, between $\sim 30$ and $\sim 75 \mathrm{~km}$, photochemistry is dominant, leading to negative ozone-temperature correlations (see their Fig. 5.11 or Fig. 11 of Garcia and Solomon, 1985). Below $\sim 25 \mathrm{~km}$ and above $\sim 85 \mathrm{~km}$, photochemistry no longer dominates, and the correlations should be positive. There are transition regions near $25-30$ and $75-85 \mathrm{~km}$, which are also somewhat latitude dependent. We note, however, that Rood and Douglass (1985) and Douglass et al. (1985) show that dynamics can at times also cause anti-correlations between temperature and ozone, so there can be exceptions.

In our analysis (Huang et al., 2008a) of ozone and temperature QBOs, SAOs, and trends (Huang et al., 2014), all also based on SABER data, we have found that the corresponding ozone-temperature correlations for these components agree with this view. This is also consistent with results based on measurements from the Microwave Limb Sounder (MLS) on UARS, as described in Huang et al. (2008a).

For altitudes including the lower thermosphere then, as discussed in Fig. 1, the ozone and temperature and their QBOs are clearly seen at both $35(32.5)$ and $60 \mathrm{~km}$ to be out of phase with each other. In contrast, at $95 \mathrm{~km}$, the ozone and temperatures, and their QBOs, are in phase (positively correlated). These are all consistent with the derived responses seen in Figs. 2 and 7.
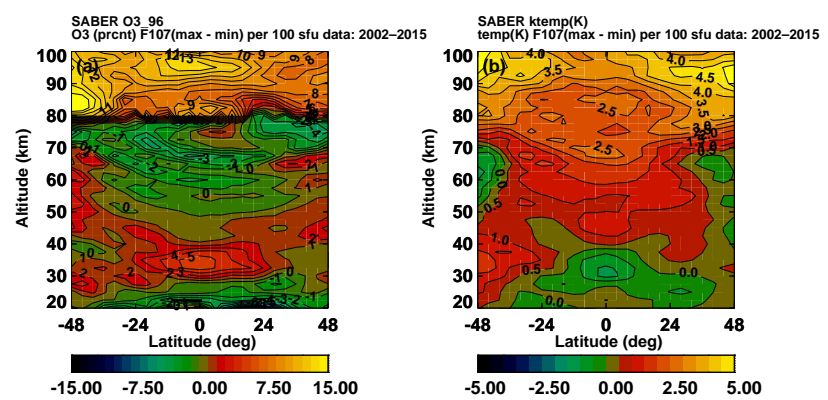

Figure 7. Ozone (left panel, $\% 100 \mathrm{sfu}^{-1}$ ) and temperature (right panel, K $\left.100 \mathrm{sfu}^{-1}\right)$ responses to solar variability on altitude (20$100 \mathrm{~km})$ vs. latitude $\left(48^{\circ} \mathrm{S}\right.$ to $\left.48^{\circ} \mathrm{N}\right)$ coordinates, corresponding to responses shown in Fig. 2 but expanded to $100 \mathrm{~km}$.

\section{Summary and discussion}

\subsection{Results}

We have derived simultaneous ozone and temperature responses to the Sun's 11-year cycle, based on measurements from SABER, which have not been available previously with this kind of spatial coverage. The simultaneous measurements of ozone and temperature allow for studying details of correlations and phase relationships between them, which provides important information and supports the quality of our results.

The ozone and temperature responses are found be positive or negative, depending on location. From $\sim 25$ to $80 \mathrm{~km}$, the ozone and temperature responses are generally out of phase (negatively correlated) as a function of solar variability, with some exceptions in the lower altitudes. These negative correlations are maintained even though the individual ozone (temperature) responses can change signs as a function of altitude and latitude, because the corresponding temperature (ozone) responses also change signs in step with each other. In contrast, from 80 to $100 \mathrm{~km}$, they are in phase for all latitudes.

Over the entire altitude range from 20 to $100 \mathrm{~km}$, these phase relationships are consistent with numerous previous studies (see Sect. 5.4; Barnett et al., 1975; Finger et al., 1995; Brasseur and Solomon, 2005) concerning the ozone mixing ratios and temperatures, albeit not specifically the component of responses to solar activity per se. However, the phase relationships are also consistent with other components such as the QBOs, SAOs, and trends, based on previous studies. The QBO ozone-temperature phase relations can be seen directly in Fig. 1.

In Sect. 5, we discussed the quality of our results, including standard errors and confidence levels, potential effects of the SABER data length and aliasing, and correlations between the data and the $10.7 \mathrm{~cm}$ flux. These are all consistent in supporting our results. 


\subsection{Comparisons}

The general magnitudes of our ozone and temperature responses are qualitatively similar to those of previous studies. However, they cannot be said to agree well in the detailed variations with most of them. Previous results do not agree so well with each other either.

In Sect. 5.4, we discussed views of other authors who point more to the data, and less to the regression analysis, as possible causes for the discrepancies.

We already noted earlier that Gray et al. (2005) attributed differences between the temperature responses obtained by Hood (2004) and other studies using SSU/MSU to corrections for instrument drift. In comments about the inconsistencies of the various studies, Crooks and Gray (2005) also state:

"We note here that tests have shown that none of the discrepancies between the current work and that of S2000 and H2004 can be explained simply in terms of the slightly different lengths of the various datasets employed, nor the fact that $\mathrm{H} 2004$ used the Mg II index to represent solar variability rather than the $10.7-\mathrm{cm}$ radio flux as was used in the current study and in S2000. We suggest that differences between the datasets employed is the primary reason for the large disagreement between the results of $\mathrm{H} 2004$ and those shown in the current analysis and in S2000."

Given these considerations, we would agree that the differences in the results of at least some previous studies, including this study, are mostly due to the quality of the data themselves rather than the regression analysis.

\section{Data availability}

The SABER data and full documentation are freely available from the SABER project at http://saber.gats-inc.com/.

Acknowledgements. We thank the editor, C. Jacobi, and three anonymous reviewers, whose insightful comments helped make the manuscript better.

The topical editor, C. Jacobi, thanks three anonymous referees for help in evaluating this paper.

\section{References}

Austin, J., Tourpali, K., Rozanov, E., Akiyoshi, H., Bekki, S., Bodeker, G., Brühl, C., Butchart, N, Chipperfield, M., Deushi, M., Fomichev, V. I., Giorgetta, M. A., Gray, L., Kodera, K., Lott, F., Manzini, E., Marsh, D., Matthes, K., Nagashima, T., Shibata, K., Stolarski, R. S., Struthers, H., and Tian, W.: Coupled chemistry climate model simulations of the solar cycle in ozone and temperature, J. Geophys. Res, 113, D11306, doi:10.1029/2007JD009391, 2008.

Barnett, J. J., Houghton, J. T., and Pyle A. J.: The temperature dependence of the ozone concentration near the stratopause, Q. J. Roy. Meteor. Soc., 101, 245-257, 1975.

Bevington, P. R. and Robinson, D. K.: Data reduction and error analysis for the physical sciences, McGraw-Hill, 328 pp., 1992.

Brasseur, G. P: The response of the middle atmosphere to long term and short-term solar variability: A two-dimensional model, J. Geophys. Res., 98, 23079-23090, doi:10.1029/93JD02406, 1993.

Brasseur, G. P. and Solomon, S.: Aeronomy of the Middle Atmosphere, Springer, 644 pp., 2005.

Crooks, S. A. and Gray, L. J.: Characterization of the 11-year solar signal using multiple regression analysis of the ERA-40 dataset, J. Clim., 18, 996-1015, 2005.

Douglass, A., Rood, R. B., and Stolarski, R. S.: Interpretation of ozone temperature correlations: 2. Analysis of SBUVozone data, J. Geophys. Res., 90, 10693-10708, 1985.

Fadnavis, S. and Beig, G.: Decadal solar effects on temperature and ozone in the tropical stratosphere, Ann. Geophys., 24, 20912103, doi:10.5194/angeo-24-2091-2006, 2006.

Finger, F. G., Nagatani, R. M., Gelman, M. E., Long, C. S., and Miller, A. J.: Consistency between variations of ozone and temperature in the stratosphere, Geophys. Res. Lett., 22, 3477-3480, 1995.

Garcia, R. R. and Solomon, S.: The Effect of Breaking Gravity Waves on the Dynamics and Chemical Composition of the Mesosphere and Lower Thermosphere, J. Geophys. Res., 90, 38503868, 1985.

Gray, L. J., Haigh, J. D., and Harrison, R. G.: A Review of The Influence of Solar Changes on the Earth's Climate, Hadley Centre, Technical Note 62, 1-81, 2005.

Gray, L. J., Rumbold, S. T., and Shine, K. P.: Stratospheric Temperature and Radiative Forcing response to 11-Year Solar Cycle Changes in Irradiance and Ozone, J. Atmos. Sci., 66, 2402-2416, 2009.

Haigh, J. D., Austin, J., Butchart, N., Chanin, M.-L., Crooks, S., Gray, L. J., Halenka, T., Hampson, J., Hood, L. L., Isaksen, I. S .A., Keckhut, P., Labitzke, K., Langematz, U., Matthes, K., Palmer, M., Rognerud, B., Tourpali, K., and Zerefos, C.: Solar variability and climate: selected results from the SOLICE projec, SPARC Newsletter, No. 23, 2004.

Hood, L. L.: Effects of solar UV variability on the stratosphere, Solar Variability and Its Effects on Climate, Geophys. Monogr., Amer. Geophys. Union, Vol. 141, 2004.

Hood, L. L. , Misios, S., Mitchell, D. M., Rozanov, E., Gray, L. J., Tourpali, K., Matthes, K., Schmidt, H., Chiodo, G., Thiéblemont, R., Shindell, D., and Krivolutsky, A.: Solar Signals in CMIP-5 Simulations: The Ozone Response, Q. J. Roy. Meteor. Soc., 141, 2670-2689, doi:10.1002/qj.2553, 2015. 
Huang, F. T., Mayr, H. G., Reber, C. A., Russell III, J. M, and Mlynczak, M. G.: and Mengel, J. G.: Ozone quasi-biennial oscillations (QBO), semiannual oscillations (SAO), and correlations with temperature in the mesosphere, lower thermosphere, and stratosphere, based on measurements from SABER on TIMED and MLS on UARS, J. Geophys. Res., 113, A01316, doi:10.1029/2007JA012634, 2008a.

Huang, F. T., Mayr, H. G., Russell III, J. M., Mlynczak, M. G., and Reber, C. A.: Ozone diurnal variations and mean profiles in the mesosphere, lower thermosphere, and stratosphere, based on measurements from SABER on TIMED, J. Geophys. Res., 113, A04307, doi:10.1029/2007JA012739, 2008b.

Huang, F. T., McPeters, R. D., Bhartia, P. K., Mayr, H. G., Frith, S. M., Russell III, J. M., and Mlynczak, M. G.: Temperature diurnal variations (migrating tides) in the stratosphere and lower mesosphere based on measurements from SABER on TIMED, J. Geophys. Res., 115, D16121, doi:10.1029/2009JD013698, 2010a.

Huang, F. T., Mayr, H. G., Russell III, J. M., and Mlynczak, M. G.: Ozone diurnal variations in the stratosphere and lower mesosphere, based on measurements from SABER on TIMED, J. Geophys. Res., 115, D24308, doi:10.1029/2010JD014484, $2010 b$.

Huang, F. T., Mayr, H. G., Russell III, J. M., and Mlynczak, M. G.: Ozone and temperature decadal trends in the stratosphere, mesosphere and lower thermosphere, based on measurements from SABER on TIMED, Ann. Geophys., 32, 935-949, doi:10.5194/angeo-32-935-2014, 2014.

Huang, F. T., Mayr, H. G., Russell III, J. M., and Mlynczak, M. G.: Ozone and temperature decadal responses to solar variability in the mesosphere and lower thermosphere, based on measurements from SABER on TIMED, Ann. Geophys., 34, 29-40, doi:10.5194/angeo-34-29-2016, 2016.

Keckhut, P., Cagnazzo, C., Chanin, M.-L., Claud, C., Hauchecorne, A.: The 11-year solar-cycle effects on the temperature in the upper-stratosphere and mesosphere: Part I - Assessment of observations, J. Atmos. Sol.-Terr. Phy., 67, 940-947, 2005.

Nath, O. and Sridharan, S.: Long-term variabilities and tendencies in zonal mean TIMED-SABER ozone and temperature in the middle atmosphere at $10-15^{\circ}$ N, J. Atmos. Sol.-Terr. Phy., 120, $1-8,2014$.

Maycock, A. C., Matthes, K., Tegtmeier, S., Thiéblemont, R., and Hood, L.: The representation of solar cycle signals in stratospheric ozone - Part 1: A comparison of recently updated satellite observations, Atmos. Chem. Phys., 16, 10021-10043, doi:10.5194/acp-16-10021-2016, 2016.

Mitchell, D. M., Misios, S., Gray, L. J., Tourpali, K., Matthes, K., Hood, L., Schmidt, H., Chiodo, G., Thieblemont, R., Rozanov, E., Shindell, D., and Krivolutsky, A.: Solar signals in CMIP-5 simulations: the stratospheric pathway, Q. J. Roy. Meteor. Soc., 141, 2390-2403, doi:10.1002/qj.2530, 2015

Mukhtarov, P., Pancheva, D., and Andonov, B.: Global structure and seasonal and interannual variability of the migrating diurnal tide seen in the SABER/TIMED temperatures between 20 and $120 \mathrm{~km}$, J. Geophys. Res., 114, A02309, doi:10.1029/2008JA013759, 2009.

Randel, W. J. and Wu, F.: A stratospheric ozone profile data set for 1979-2005: Variability, trends, and comparisons with column ozone data, J. Geophys. Res, 112, D06313, doi:10.1029/2006JD007339, 2007.
Randel, W. J., Shine, K. P., Austin, J., Barnett, J., Claud, C., Gillett, N. P., Keckhut, P., Langematz, U., Lin, R., Long, C., Mears, C., Miller, A., Nash, J., Seidel, D. J., Thompson, D. W. J., Wu, F., and Yoden, S.: An update of observed stratospheric temperature trends, J. Geophys., 114, D02107, doi:10.1029/2008JD010421, 2009.

Remsberg, E. E.: On the response of Halogen Occultation Experiment (HALOE) stratospheric ozone and temperature to the 11-year solar cycle forcing, J. Geophys. Res., 113, D22304, doi:10.1029/2008JD010189, 2008.

Rood, R. B. and Douglass, A.: Interpretation of Ozone Temperature Correlations: 1. Theory, J. Geophys. Res., 90, 5733-5743, 1985.

Russell III, J. M., Mlynczak, M. G., Gordley, L. L., Tansock, J., and Esplin, R.: An overview of the SABER experiment and preliminary calibration results, Proceedings of the SPIE, 44th Annual Meeting, Denver, Colorado, 18-23 July 1999, 3756, 277-288, 1999.

Scaife, A. A., Austin, J., Butchart, N., Keil, M., Pawson, S., Nash, J., and James, I. N.: Seasonal and interannual variability of the stratosphere diagnosed from UKMO TOVS analyses, Q. J. Roy. Meteor. Soc., 126, 2585-2604, 2000.

She, C. Y., Krueger, D. A., Akmaev, R., Schmidt, H., Talaat, E., and Yee, S.: Long-term variability in mesopause region temperatures over FortCollins, Colorado $\left(41^{\circ} \mathrm{N}, 105^{\circ} \mathrm{W}\right)$ based on lidar observations from 1990 through 2007, J. Atmos. Sol.-Terr. Phy., 71, 1558-1564, 2009.

Shindell, D., Rind, D., Balachandran, J., Lean, J., and Lonergran, P.: Solar cycle variability, ozone and climate, Science, 284, 305308, 1999.

Soukharev, B. E. and Hood, L. L.: The solar cycle variation of stratospheric ozone: Multiple regression analysis of long-term satellite data sets and comparisons with models, J. Geophys. Res., 111, D20314, doi:10.1029/2006JD007107, 2006.

Taylor, K. E., Stouffer, R. J., and Meehl, G. A.: An overview of CMIP5 and the experiment design, B. Am. Meteorol. Soc., 93, 485-498, 2012.

Tiao, G. C., Reinsel, G. C., Xu, D., Pedrick, J. H., Zhu, X., Miller, A. J., DeLuisi, J. J., Mateer, C. L., and Wuebbles, D. J.: Effects of autocorrelation and temporal sampling schemes on estimates of trend and spatial correlation, J. Geophys Res., 95, 20507-20517, 1990.

Weatherhead, E. C., Reinsel, G. C., Tiao, G. C., Meng, X.-L., Hoi, D. C., Cheang, W.-K., Keller, T., DeLuisi, J., Wuebbles, D. J., Kerr, J. B., Miller, A. J., Oltmans, S. J., and Frederick, J. E.: Factors affecting the detection of trends: Statistical considerations and applications to environmental data, J. Geophys. Res., 103, 17149-17161, 1998.

Weatherhead, E. C., Reinsel, G. C., Tiao, G. C., Jackman, C. H., Bishop, L., Hollandsworth Frith, S. M., DeLuisi, J., Keller, T., Oltmans, S. J., Fleming, E. L., Wuebbles, D. J., Kerr, J. B., Miller, A. J., Herman, J., McPeters, R., Nagatani, R. M., and Frederick, J. E.: Detecting the recovery of total column ozone, J. Geophys. Res., 105, 22201-22210, 2000.

Zhang, X., Forbes, J. M., Hagan, M. E., Russell III, J. M., Palo, S. E., Mertens, C. J., and Mlynczak, M. G.: Monthly tidal temperatures 20-120 km from TIMED/SABER, J. Geophys. Res., 111, A10S08, doi:10.1029/2005JA011504, 2006. 